\title{
Antibacterial Activity of Copper and Cobalt Amino Acids Complexes
}

\author{
Andreea STĂNILĂ ${ }^{1}$, Cornelia BRAICU², Sorin STĂNILĂ', Raluca M. POP ${ }^{1}$ \\ ${ }^{1}$ University of Agricultural Science and Veterinary Medicine, 3-5 Mănăştur Street, 400372, Cluj-Napoca, Romania; andreea7s@yahoo.com \\ ${ }^{2}$ The Oncology Institute "Prof. Dr. Ion Chiricuță", 34-36 Republicii Street, 400015, Cluj-Napoca, Romania
}

\begin{abstract}
The antibacterial properties of differently copper and cobalt amino acids complexes on agar plates was investigated in the present study. The antibacterial activity of amino acid complexes was evaluated against on three bacteria strains (Escherichia coli, Bacillus cereus, Micrococcus luteus). Generally, the amino acids complexes were mainly active against gram-positive organisms, species like Micrococcus luteus being the most susceptible strain tested. It was registered a moderate antibacterial activity against Bacilluscereus. The microorganisms Escherichia coli, which are already known to be multi-resistant to drugs, were also resistant to the amino acids complexes but also to the free salts tested. Escherichia coli were susceptible only to the $\mathrm{CoCl}_{2}$ and copper complex with phenylalanine. The complexes with leucine and histidine seem to be more active than the parent free ligand against one or more bacterial species. Moderate activity was registered in the case of complexes with methionine and phenylalanine. From the complexes tested less efficient antibacterial activity was noted in the case of complexes with lysine and valine. These results show that cobalt and copper complexes have an antibacterial activity and suggest their potential application as antibacterial agents.
\end{abstract}

Keywords: antibacterial agents, chelates, gram-positive microorganisms, histidine complexes

\section{Introduction}

In general, bacteria have the genetic ability to send and acquire resistance to drugs, which are used as therapeutic agents. Even if pharmaceutical industry produce a lot of new antibiotics in the last three decades, the resistance of microorganisms to these drugs has increased (Faúndez et al., 2004).

The microbial resistance represent a problem and the outlook for the use of antimicrobial drugs in the future is still uncertain. Therefore, it must be taken measures to reduce this problem, for example, to control the use of antibiotic, develop research to better understand the genetic mechanisms of resistance, and to continue studies to develop new drugs, either synthetic or natural. The ultimate goal is to offer appropriate and efficient antimicrobial drugs to the patient (Kabbani et al., 2004). For centuries, people have used copper and cobalt ions to inhibit the growth of harmful microbes.

Coordination complexes of transition metals have been widely studied for their antibacterial, antifungal and potential cytotoxic chemotherapeutic agents. They have been evaluated against several pathogenic fungi and bacteria with promising results. One of the approaches to increases the efficacy of the drugs consists in their modification of physical and chemical factors. In addition to its ability to combat infection or neoplastic disease, these new agents must exhibit selective toxicity, chemical stability, and optimum rates of bio-transformation and elimination (Johari et al., 2009).
The aim of the present study was to evaluate the antifungal and antibacterial properties of a range of copper (II) and cobalt (II) complexes with different amino acids comparing with free ligand and as reference standard was used Flumequine. The antimicrobial efficiency of the amino acids complex has been tested on three different bacteria strains (Escherichia coli, Bacillus cereus, Micrococcus luteus).

\section{Material and methods}

Copper and cobalt amino acids synthesis

There were synthesised six amino acids complexes with copper ions using as ligands methionine, phenylalanine, valine, leucine, lysine ( $\mathrm{Cu}-\mathrm{Met}, \mathrm{Cu}-\mathrm{Phe}, \mathrm{Cu}-\mathrm{Val}, \mathrm{Cu}-\mathrm{Leu}$, respectively $\mathrm{Cu}$-Lys) and five amino acids complexes with cobalt ions and methionine, phenylalanine, leucine, lysine as ligands (Co-Met, Co-Phe, Co-Leu, respectively CoLys). All amino acids were synthesized in the Chemistry and Biochemistry Department of USAMV.

The purpose of the study was to obtain neutral complexes of $\left[\mathrm{Co}\left(\mathrm{LH}_{2} \mathrm{O}\right)_{2}\right] \cdot \mathrm{nH}_{2} \mathrm{O}$ and $\left[\mathrm{Cu}\left(\mathrm{LH}_{2} \mathrm{O}\right)_{2}\right]$ type at $\mathrm{pH}=8-10$, in the presence of a strong basis $(\mathrm{NaOH})$ to obtain the ionization conditions of the amino acid.

The complexes were prepared following the procedure: 2 mmols of all ligands were dissolved in $20 \mathrm{ml}$ distilled water and for deprotonation of the amino acids $0.33 \mathrm{ml} \mathrm{30 \%}$ $\mathrm{NaOH}$ was added (Stanila et al., 2007). Then $1 \mathrm{mmol}$ of the metal salts was dissolved in $2 \mathrm{ml}$ of distilled water, and was added to the deprotonated amino acid solution under 
stirring for several minutes. The precipitate was filtered off, washed with water several times, and dried in air.

For all the amino acids, the precipitation was instantaneous, and the colour was pink for cobalt complexes and blue for copper complexes. The compounds were found to be soluble in methanol, ethanol, DMSO or DMF.

\section{Microbial strains}

The amino acids were tested against the following microorganisms: Escherichia coli, Micrococcus luteus, Bacilus cereus. Bacterial strains provided from MTC Romania, were cultured overnight at $37^{\circ} \mathrm{C}$ in agar.

Pre-culture of test bacteria for $24 \mathrm{~h}$ with a $250 \mathrm{ml}$ peptone broth (Difco Laboratories) produced a stock preparation containing a log-phase cell density of approximately $10^{7}$ colony forming units (CFU)/ml as evaluated initially by measurements of the optical density at $600 \mathrm{~nm}$.

\section{Antibacterial assay}

Antibacterial tests were then carried out by disc diffusion method ( $\mathrm{Pal}$ et al., 2007), using $100 \mu \mathrm{l}$ of suspension containing $10^{7} \mathrm{CFU} / \mathrm{ml}$ of bacteria, spread on nutrient agar. The discs ( $6 \mathrm{~mm}$ in diameter) were impregnated with the $25 \mu \mathrm{l} /$ disc stock solution of $10^{-3} \mathrm{M}$ (a) respectively $10^{-4} \mathrm{M}$ (b) of amino acids complexes and placed on the inoculated agar. Negative controls were prepared using DMSO. Flumequine $(25 \mu \mathrm{g} /$ disc $)$ was used as positive reference standards to determine the sensitivity of each bacterial species tested. The inoculated plates were incubated at $37^{\circ} \mathrm{C}$ for $48 \mathrm{~h}$. Antibacterial activity was evaluated by measuring the zone of inhibition against the test organisms. All inhibitory tests were performed in triplicate. An average of two independent readings for each compound was recorded. Finally, Petri plates were incubated for 2630 hours $28 \pm 2^{\circ} \mathrm{C}$. The zone of inhibition was calculated in millimetres carefully.

\section{Results}

Many microorganisms, which cause damage to human health, exhibit drug resistance due to inadequate use of antibiotics. Thus, there is a need for the discovery of new substances from natural sources.

Complexes of copper and cobalt with essential amino acids $\left[\mathrm{Cu}-\left(\mathrm{L}_{1}\right)_{2}\right] \mathrm{H}_{2} \mathrm{O}$ and $\left[\mathrm{Co}-\left(\mathrm{L}_{2}\right)_{2}\right] \mathrm{H}_{2} \mathrm{O}$ were synthesized in aqueous solution and analyzed by means of elemental analysis, thermogravimetric and differential analysis, atomic absorption, IR, UV-VIS and EPR spectroscopies.

The elemental analysis measurements of the carbon, nitrogen, hydrogen and sulphur content, confirm that the composition corresponded to a metal:ligand ratio in all the Co(II) complexes was found to be 1:2 .

The IR spectra show that the amino acids act as bidentate ligands with coordination involving the carboxyl oxygen and the nitrogen atom of amino group.

Informations about the ions coordination were obtained by comparing the IR frequencies of the ligands with those of the metal complexes. IR spectra demonstrate that amino acids act as bidental ligands by involving the amino
(A)

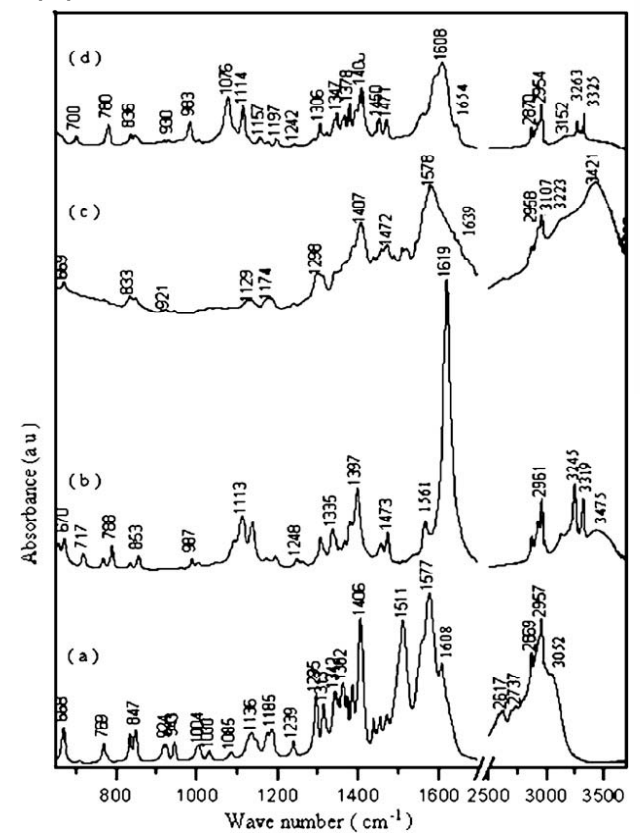

(B)

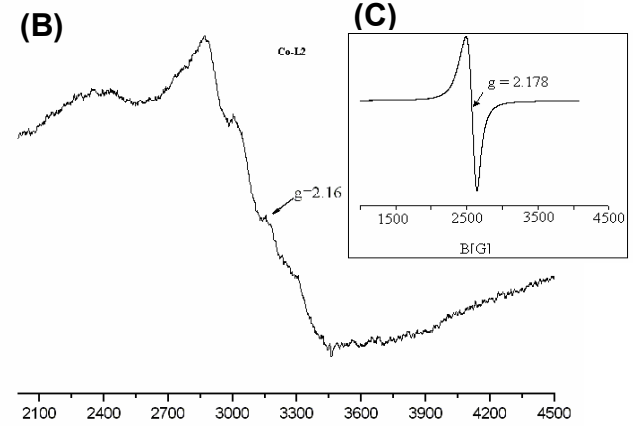

(D)

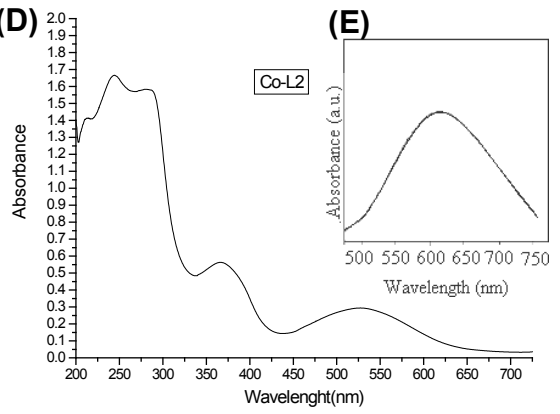

Fig. 1. IR Spectra of leucine and leucine-copper, cobalt and zinc complex (A); Powder EPR spectra of cobaltleucine complex at room temperature(B); Powder EPR spectrum of copper complex at room temperature (C); UV-Visible Spectra of leucine-cobalt complex in water (D); Visible spectra of copper complex in DMSO (E) 
126

and carboxyl groups in coordination with metallic ions (Fig. 1A). In the spectra of the ligand the $v(\mathrm{~N}-\mathrm{H})$ stretching vibrations appear at $3052 \mathrm{~cm}^{-1}$. This band appear to be shifted toward higher frequencies in the spectra of the complex with $55 \mathrm{~cm}^{-1}$ for copper complex proving the involvement of the $-\mathrm{NH}_{2}$ group in the complex formation (Batiu et al., 2005).

The $v(\mathrm{O}-\mathrm{H})$ stretching vibration does not appear in the spectra ligand, but it do in spectra of the complex at $3421 \mathrm{~cm}^{-1}$, suggesting the presence of the crystal and coordinated water in this compound.

The absorption band at $1624 \mathrm{~cm}^{-1}$ was attributed to the $v(\mathrm{C}=\mathrm{O})$ stretching vibration in the ligand spectrum and appears to be shifted to $1608 \mathrm{~cm}^{-1}$ for complex The consecutive bands at 1600 and $1527 \mathrm{~cm}^{-1}$, in the spectrum of the ligand were assigned to the symmetric and asymmetric bending vibrations of $\mathrm{N}-\mathrm{H}$ bond. In the spectrum of the complex are shifted to $1578 \mathrm{~cm}^{-1}$ and $1584 \mathrm{~cm}^{-1}$, which also indicates the involvement of this group in the metalligand bond formation.

$\mathrm{UV}-\mathrm{Vis}$ and electron spin resonance (EPR) spectra shows typical species monomer and tetrahedral symmetry for the copper complexes and octahedral for the

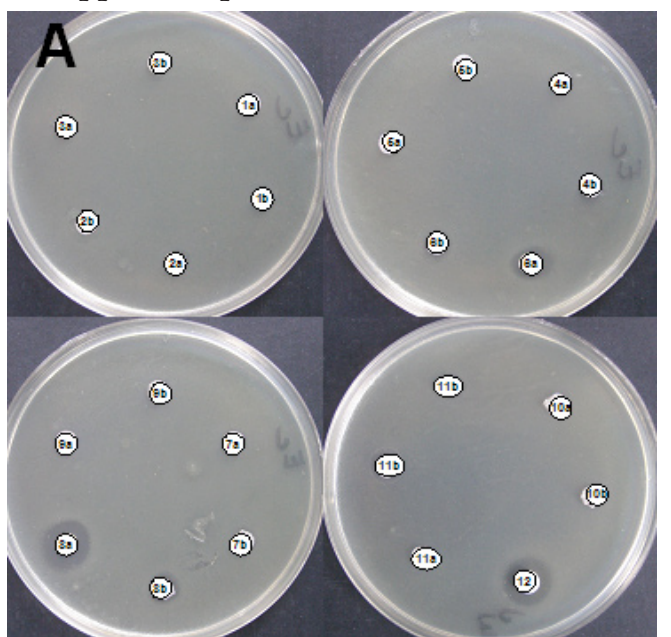

cobalt (Fig. 1 A, D, E) (Marcu et al., 2008; Stanila et al., 2007). Powder EPR spectra at room temperature are typical for monomeric species with octahedral local symmetry around the metal ion and are strongly affected by noise. Powder EPR spectrum at room temperature for copper complex is quasi-isotropic $(\mathrm{g}=2.178)$ and is characteristic for pseudotetrahedral symmetry around the copper ion (Marcu et al., 2008; Stanila et al., 2007).

The antibacterial activity of amino acids complexes was investigated against isolated grampositive strain (Bacillus cereus, Micrococcus luteus) and one standard gramnegative bacteria (Escherichia coli). Generally the amino acids complexes were mainly active against grampositive. The results of the antimicrobial screening by agar diffusion are showed in Fig. 2.

One of the microorganisms that showed a susceptibility to these amino acids complexes was Micrococcus luteus. It has been registered a moderate antibacterial activity against Bacillus cereus. Such results were not totally unexpected since these bacteria form resting spores and are more resistant to environmental conditions than any other tested bacteria. Escherichia coli, which are already known to be multi-resistant to drugs, were also resistant to the
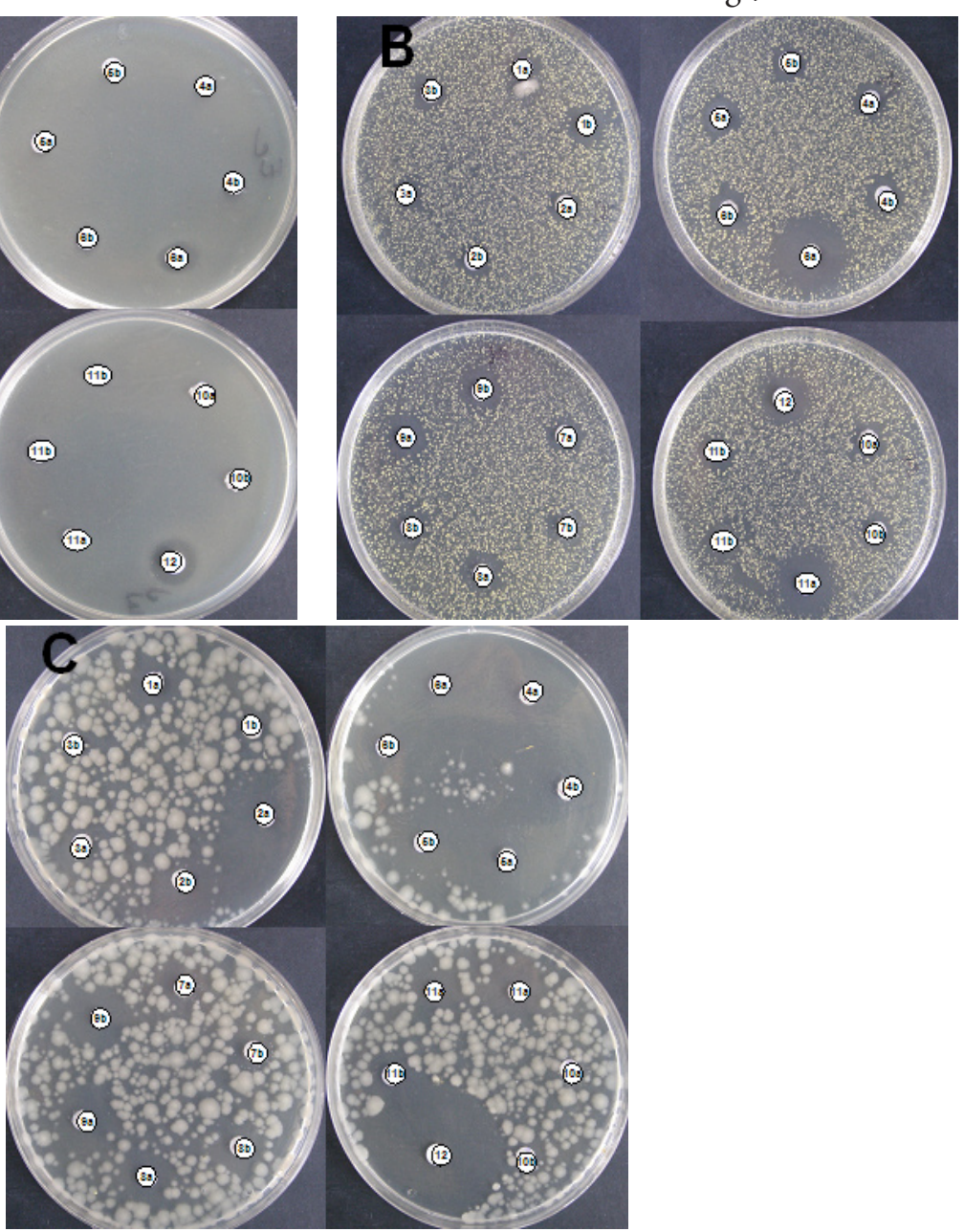

Fig. 2. Agar diffusion assay for antibacterial-screening results against human pathogenic bacteria against Escherichia coli (A); against Bacillus cereus (B); against Micrococcus luteus (C) 
amino acids complexes but also to the free salts tested. Escherichia coli were susceptible only to the $\mathrm{CoCl}_{2}$ and $\mathrm{Cu}-$ Phe. Such results are very interesting, because this bacterium was standard strain.

The values for diameter of inhibition zone of the tested amino acids complexes ranged from 0 to $30 \mathrm{~mm}$ depending on the bacterial strain and the type of amino acid used for chelating the transitional metal (Tab. 1).

A difference in antibacterial activity has been observed for Bacillus cereus in the following order: $\mathrm{Cu}-\mathrm{Leu}>\mathrm{Cu}-$ $\mathrm{His} \approx \mathrm{Cu}-\mathrm{Cl}_{2}>\mathrm{Cu}-\mathrm{Phe}>\mathrm{Co}-\mathrm{Phe} \approx \mathrm{Co}-\mathrm{Leu} \approx \mathrm{CoCl}_{2}>$ $\mathrm{Cu}-\mathrm{Met}>\mathrm{Co}-\mathrm{Met}>\mathrm{Cu}-\mathrm{Val}>\mathrm{Co}$-Lys, while for Micrococus luteus the order was: $\mathrm{Cu}-\mathrm{Cl}_{2} \approx \mathrm{CoCl}_{2}>\mathrm{Co}$ - $\mathrm{Phe} \approx \mathrm{Cu}-$ $\mathrm{His}>\mathrm{Cu}-\mathrm{Met}>\mathrm{Cu}-\mathrm{Leu} \approx \mathrm{Co}-\mathrm{Met} \approx \mathrm{Co}-\mathrm{Leu} \approx \mathrm{Co}-\mathrm{Lys}>$ $\mathrm{Cu}-\mathrm{Val} \approx \mathrm{Cu}-\mathrm{Val}$, based on the measurement diameter of inhibition zone (Tab. 1).

The results show a variable effect of amino acids complexes on the microorganisms. All complexes studied, presented moderate to high activity against Micrococcus luteus and Bacillus cereus. In most of the cases was registered a relation dose-effect. Complexes with leucine and histidine

Tab. 1. The zone of inhibition ( $\mathrm{mm}$ ) of copper and cobalt amino acids complexes prepared at different conditions against test strains

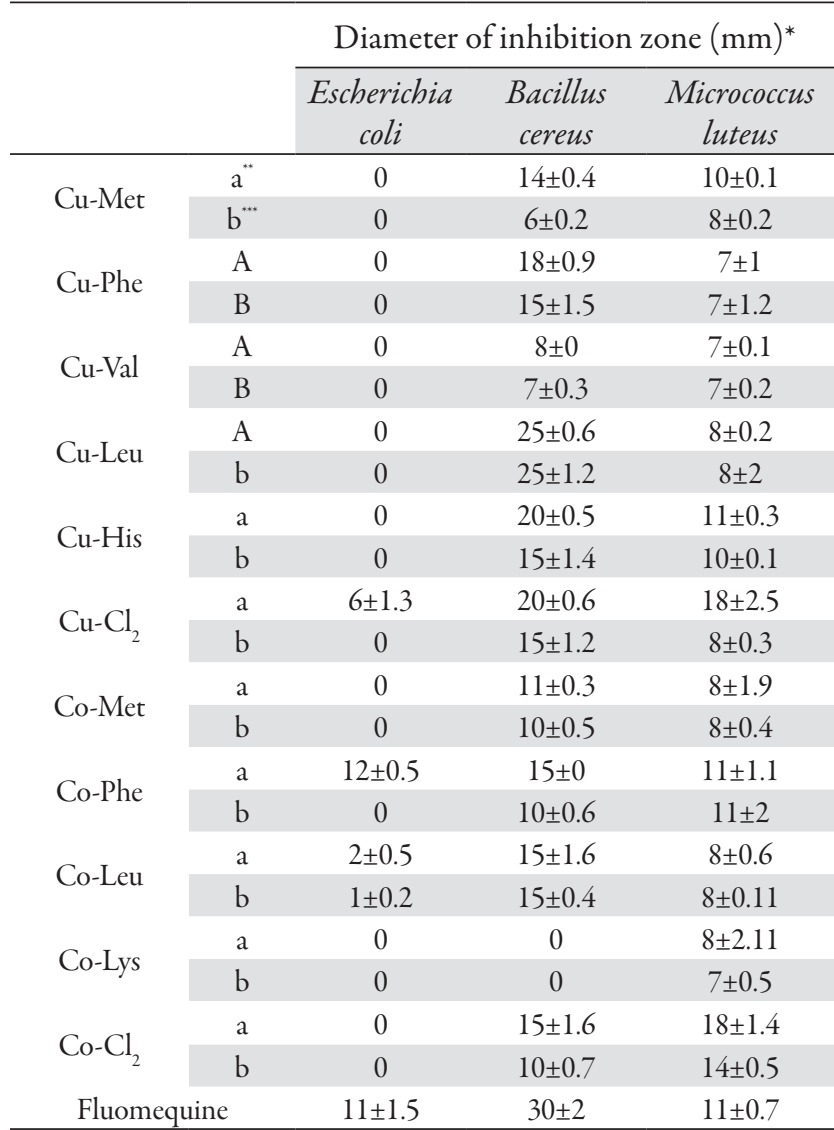

${ }^{*}$ The diameter of the inhibition zone including disc diameter of $6(\mathrm{~mm})$. Values are means the average of three replications \pm SD; ${ }^{* *} 25 \mu \mathrm{l} /$ disc of stock solution of 10-3 M of amino acids complexes and placed on the inoculated agar; ${ }^{* * *} 25 \mathrm{\mu l} /$ disc of stock solution of $10-4 \mathrm{M}$ of amino acids complexes and placed on the inoculated agar seem to be more active than the parent free ligand against one or more bacterial species. Moderate activity was registered in the case of complexes with methionine and phenylalanine. From the complexes tested less efficient antibacterial activity was noted in the case of complexes with lysine and valine.

Finally, regarding to effects of the antibiotics used as positive control, Bacillus cereus it has been registered a higher antibacterial meanwhile for the other two bacterial strains a moderate activity.

\section{Discussion}

The objective of this study was to evaluate the antibacterial activity of copper and cobalt amino acids complexes. Copper amino acids complexes were proven to have a higher antibacterial activity than those with cobalt, results confirmed by another study focused on the evaluation the antifungal effect of those newly agents (Braicu et al., 2006; Faúndez et al., 2004). These studies emphasis the utility, especially copper complexes as newly alternative antibacterial therapeutic agents.

Gram-positive bacteria are known to be more susceptible to amino acids complexes than gram-negative bacteria. The finding that Escherichia coli was least susceptible to the five copper and four cobalt amino acids complexes in this investigations is in accord with previously studies (Faúndez et al., 2004; Kabbani et al., 2004).

The weak antibacterial activity against gram negative bacteria was ascribed to the presence of an outer membrane which poses hydrophilic polysaccharides chains as a barrier to the amino acids complexes.

It has been reported that the antibacterial activity of a complex is influenced by its stability. The lower stability of the amino acid complex, the greater is the antibacterial activity. This is probably because they have more free ions in the solution, which can enhance the cooperative interaction between the metal ions and the ligands (Marcu et al., 2008; Stanila et al., 2007). This can explain the different antibacterial activity of the copper and cobalt complexes depending on the amino acid type. Another possibility is linked to the fact that the activity in the chelated complex, the positive charge of the metal is partially shared with the donor atoms present in the ligands and there is $\pi$-electron delocalization over the whole chelate ring. This in turn increases the lipophilic character of the metal chelate and favors its permeation through the lipoid layers of the bacterial membranes. Apart from this, other factors such as solubility, conductivity and dipole moment (influenced by the presence of metal ions; Chohan and Mushtaq, 2000) may also be the possible reasons for increasing this activity in the case of Bacillus cereus that free salts.

As it can be see from Tab. 1 the zone of inhibition for some amino acids complexes ( $\mathrm{Cu}-\mathrm{Leu}, \mathrm{Cu}-\mathrm{His})$ is higher than for the free salts in the case of gram-positive bacteria (Bacillus cereus). The increased activity of the metal 
128

chelates can be explained on the basis of chelation theory (Sengupta et al., 1998). It is known that chelation tends to make the ligand act as more powerful and potent bactericidal agents, thus killing more of the bacteria than the ligand. It has been observed that, in a complex, the positive charge of the metal is partially shared with the donor atoms present in the ligands, and there may be $\pi$-electron delocalization over the whole chelating (Sengupta et al., 1998). This increases the lipophilic character of the metal chelate and favours its permeation through the lipoid layer of the bacterial memberanes (Chandra et al., 2007). There are other factors which also increase the activity, which are solubility, conductivity, and bond length between the metal and the ligand, which may explain the values resisted in the present case.

In a similar study it was demonstrate that cobalt (III) complexes with pyridine-amide ligands show mild to moderate activity against standard and pathogenic resistant bacteria. The results reveal that these complexes can act as potent antimicrobial agents (Mishra et al., 2008), with an reduced level of cytotoxicity, all complexes were less cytotoxic than gentamycin on HEK cell lines.

The mode of action may involve the formation of a hydrogen bond through the azomethane nitrogen atom with the active centers of the cell constituents, resulting in interference with the normal cell process. The variation in the effectiveness of different compounds against different organisms depends either on the impermeability of the cells of the microbes or the difference in ribosomes of microbial cells. It has also been proposed that concentration plays a vital role in increasing the degree of inhibition; as the concentration increases, the activity increases as it was reported also in the present cases (El-Wahab et al., 2005).

The interaction of metal ions with drugs administered for therapeutic purposes is a subject of considerable interest. It is known that some drugs work by chelation or inhibiting the formation of metalloenzymes. Therefore metal ions might play a vital role during the biological process of drug utilization in the body. In this context further studies are needed to understanding the antibacterial or antifungal mechanism (Faúndez et al., 2004).

Studies regarding the mode of action for these compounds in the bacterial cell should be done, since these substances are natural, their hazardous potential is lower when compared with other products taking in account that The Recommended Dietary Intake (RDI) for copper is $0.9 \mathrm{mg}$ for adults, while the upper limit of intake for this metal is $10 \mathrm{mg}$ for the same population for cobalt RDI being between $10 \mu \mathrm{g}-20 \mu \mathrm{g}$ (http://www.acu-cell.com/ nico2.html).

\section{Conclusions}

The results show that amino acids complexes have inhibitory effect against Micrococcus luteus and Bacillus cereus and less efficient against Escherichia coli. More in the case of Bacillus cereus antibacterial activity being much stronger than free salts.

Therefore, the present results revealed the importance of amino acids complexes and can be associated with antibiotics, to control resistant bacteria, which are becoming a threat to human health. Furthermore, these amino acids complexes were active against bacteria under very low concentration, thus minimizing the possible toxic effects.

These results show that cobalt and copper complexes have an antibacterial activity and suggest its potential application as potential antibacterial agents, in the field of disinfection, food packaging and piping of drinking water.

\section{Acknowledgements}

This work was funded by the National Research Grant IDEI no.1114/2009 financed by UEFISCDI- Romania.

\section{References}

Batiu C, Jelic C, Leopold N, Cozar O, David L (2005). Spectroscopic investigations of new $\mathrm{Cu}(\mathrm{II}), \mathrm{Co}(\mathrm{II}), \mathrm{Ni}(\mathrm{II})$ complexes with $\gamma$-L-glutamyl amide as ligand. J Mol Struct 744-747:325-330.

Braicu C, Stanila A, Rotar M-A, Petran M, Socaciu C (2006). Antifungal activity of some amino acids complexes against Candida albicans. Bulletin USAMV Agriculture 62:207212.

Braicu C, Stanila A, Socaciu C (2006). Studies for evaluation the effect of some aminoacids complex using Sacharomyces cerevisiae as a in vitro model for cytotoxicity. Proc $41^{\text {st }}$ Croatian Internat Symp on Agricult, Opatija, 169-170 p.

Chandra S, Raizada S, Tyagi M, Gautam, A (2007). Synthesis, spectroscopic, and antimicrobial studies on bivalent nickel and copper complexes of bis (thiosemicrbazone). Bioinorg Chem Appl (1): 51483.

Chohan Z, Mushtaq S (2000). Antibacterial cobalt(Ii) and zinc(Ii) complexes of pyrazine-derived Nno and Nnn donor Schiff-bases. Pak J Pharm Sci 13(1):21-27.

Cohen ML(1992). Epidemiology ofdrugresistance:implications for a post-antimicrobial era. Science 257(5073):1050-1055.

El-Wahab ZHA, Mashaly MM, Salman AA, El-Shetary BA, Faheim AA (2004). Co(II), Ce(III) and UO2VI) bissalicylatothiosemicarbazide complexes: binary and ternary complexes, thermal studies and antimicrobial activity. Spectrochim Acta A 60(12):2861-2873.

Faúndez G, Troncoso M, Navarrete P, Figueroa G (2004). Antimicrobial activity of copper surfaces against suspensions of Salmonella enterica and Campylobacter jejuni. BMC Microbiol 4:19-26.

Farouk AEl-A, Ghouse HF, Ridzwan BH (2007). New bacterial species isolated from Malaysian sea cucumbers with optimized secreted antibacterial activity. Am J Biochem Biotechnol 3(2):60-65. 
Inouye S, Takizawa T, Yamaguchi H (2001). Antibacterial activity of essential oils and their major constituents against respiratory tract pathogens by gaseous contact. J Antimicrob Chemother 47:565-573.

Johari R, Kumar G, Kumar D, Singh S (2009). Synthesis and antibacterial activity of M(II) Schiff-Base complex. J Ind Council Chem 26(1):23-27

Kabbani AT, Hammud HH, Ghannoum AM (2007). Preparation and antibacterial activity of copper and cobalt complexes of 4-chloro-3-nitrobenzoate with a nitrogen donor ligand. Chem Pharm Bull 55(3):446-450.

Marcu A, Stanila A, Cozar O, David L (2008). Structural investigations of some metallic complexes with threonine as ligand. J Optoelectron Adv M 10(4):830-833.

Mishra A, Kaushik N, Verma A, Gupta R (2008). Synthesis, characterization and antibacterial activity of cobalt (III) complexes with pyridine-amide ligands. Eur J Med Chem 43(10):2189-2196.

Pal S, Kyung TY, Myong SJ (2007). Does the antibacterial activity of silver nanoparticles depend on the shape of the nanoparticle? A study of the gram-negative bacterium Escherichia col. Appl Environ Microbiol 73(6):1712-1720.
Sengupta SK, Pandey OP, Srivastava BK, Sharma VK (1998). Synthesis, structural and biochemical aspects of titanocene and zirconocene chelates of acetylferrocenyl thiosemicarbazones. Transit Metal Chem 23(4):349-353.

Stanila A, Marcu A, Rusu D, Rusu M, David L (2007). Spectroscopic studies of some copper (II) complexes with amino acids. J Mol Struct 834:364-368.

Vukčević M, Kalijadis A, Dimitrijević-Branković S, Laušević Z, Laušević M (2008). Surface characteristics and antibacterial activity of a silver-doped carbon monolith. Sci Technol Adv Mater 9(1):01-07.

Yang L, Tao D, Yang X, Li Y, Guo Y (2003). Synthesis, Characterization, and Antibacterial Activities of Some Rare Earth Metal Complexes of Pipemidic Acid. Chem Pharm Bull 51(5):494-498.

www.acu-cell.com 